\title{
THE INFLUENCE OF SOME FACTORS ON THE TIMBER DRYING PROCESS, ANALYZED BY A GLOBAL SIMULATION MODEL\&
}

Jarl-Gunnar Salin

\begin{abstract}
A model for the simulation of timber drying in a batch kiln has been used for the investigation of a set of different questions related to this drying process. The model is global in the sense that it takes into account that the drying air local climate changes as it passes through the kiln load. In Scandinavian, practice kiln stacks are normally built from boards of random lengths so that every second board is located flash at one end of the stack and the other boards flash at the other end. This kiln stack geometry is also included, as well as airflow reversal.
\end{abstract}

This model has been utilized to investigate the following situations:

The effect of sticker thickness on airflow, drying time and final MC standard deviation is illustrated.

Thicker stickers mean less timber in a given kiln, but results in shorter drying time. The kiln drying capacity is not influenced very much, but the final MC spread is decreased.

The influence of kiln parameters on the final MC standard deviation is investigated and simple formulas are presented for the estimation of this variation.

Keywords: wood drying, simulation

\section{INTRODUCTION}

There has always been a wish to increase the size of timber drying kilns in order to decrease the investment cost for the kiln, calculated per timber volume. As the drying air passes through the timber stack, it is cooled and moistened, i.e. the climate is different in different parts of the kiln. There is thus a tendency that the final MC spread (standard deviation) will increase as the kiln size increases. This problem is partly, but not completely, solved by a frequent airflow direction reversal. In Scandinavian practice, kiln stacks are normally built from boards of random length so that every second board is located flash at one end of the stack, and the other boards flush at the other end. This produces a center part of the stack where all positions are filled, and end parts of the stack where every second position is empty. This situation will also increase the difference in drying behavior in different parts of the kiln stack. At the same time, however, quality aspects are becoming more important, resulting in a demand to decrease the final MC spread.

A timber drying simulation model has been developed that is able to analyze the questions mentioned. The model, called TorksimGlobal, has been described earlier (Salin, 2001). The model calculates the individual drying behavior of each board in one board layer throughout the kiln, taking into account the variation in local drying air properties as a result of the wood/air interaction. As further a section of each board is located within the stack end part and the rest within the stack center part, these sections are considered separately. Finally, the airflows through the center and end parts as well as the stack bypass and their mixing behavior are included in the model.

\footnotetext{
Swedish Institute for Wood Technology Research. P.O.Box 5609, SE-114 86 Stockholm, Sweden.

Corresponding author: JarlGunnar.Salin@tratek.se

Received: August 01, 2005. Accepted: October 17, 2005.
} 
The TorksimGlobal model is thus a rather comprehensive tool to investigate different questions related to the timber drying process. In (Salin, 2001) some aspects were discussed and in the following a few other questions are considered.

\section{INFLUENCE OF STICKER THICKNESS}

The thickness of the stickers separating board layers in a kiln stack has frequently been the subject of discussion. With thinner stickers more timber can be loaded into a given kiln. This results, however, in longer drying times and in an increased final MC spread, as it is more difficult to get enough air, and thus drying capacity, into each space between board layers. The relationship between these variables is now studied by the simulation technique for a specific case.

Consider, as an example, drying of $50 \times 100 \mathrm{~mm}^{2}$ Scots pine in a kiln with a blow depth of $5 \mathrm{~m}$. Blow depth is defined as the sum of the widths of the boards in the air flow direction. The sticker thickness is $25 \mathrm{~mm}$ and the air velocity between board layers is $3 \mathrm{~m} / \mathrm{s}$, fan reversal is done every 60 minutes and all other features are according to normal Scandinavian procedures. Now the question is, what happens if the stickers are changed to either $32 \mathrm{~mm}$ or $19 \mathrm{~mm}$ thickness and all other kiln data are kept constant.

The first question to solve is how the air velocity is affected. If for instance $32 \mathrm{~mm}$ stickers are used, then there is more void space in the stack and more air is needed to maintain the same velocity. On the other hand, the airflow resistance in the stack is decreased. The result depends naturally on fan characteristics and kiln geometry, but it can be foreseen that the velocity change should not be very marked. If it is assumed that the point of operation for the fans stays within the most favorable area and that about half of the flow resistance is in the timber stack and the other half consists of resistance in heating coils, ducts, etc., then the change in velocity can be estimated. For $32 \mathrm{~mm}$ stickers the result is $2.77 \mathrm{~m} / \mathrm{s}$ and for $19 \mathrm{~mm}$ stickers $3.20 \mathrm{~m} / \mathrm{s}$.

The influence of the sticker thickness depends of course on the drying schedule used in each case. Here it is assumed that the average (pressure/suction side) dry bulb temperature is $80^{\circ} \mathrm{C}$ and constant (after a normal heating up procedure). The wet bulb temperature is decreasing and determined according to the criterion that the stress should remain below the critical value (checking) everywhere in the stack, regardless of board initial MC, heartwood content etc. The drying schedule has thus to be adapted as the stickers are changed. This is done with the simulation model and finally the drying curves are obtained and presented in Figure 1. As is seen, the drying time is shorter for $32 \mathrm{~mm}$ stickers and longer for $19 \mathrm{~mm}$ stickers, compared to the reference case. It is, however, more interesting to compare the change in kiln drying capacity, i.e. drying time per volume of timber. This is done in Figure 2 where the drying time is adjusted according to the volume of timber in the kiln. This reflects thus the relative capacity of the kiln. Now all three curves are very close to each other. For a rather high final MC the 19 mm sticker case gives a slightly lower capacity. For very low MC the $32 \mathrm{~mm}$ sticker case gives a slightly lower capacity. However, within the normal final MC range, the differences are small compared to the general accuracy of the calculation and the result may change if the input data details are changed. 


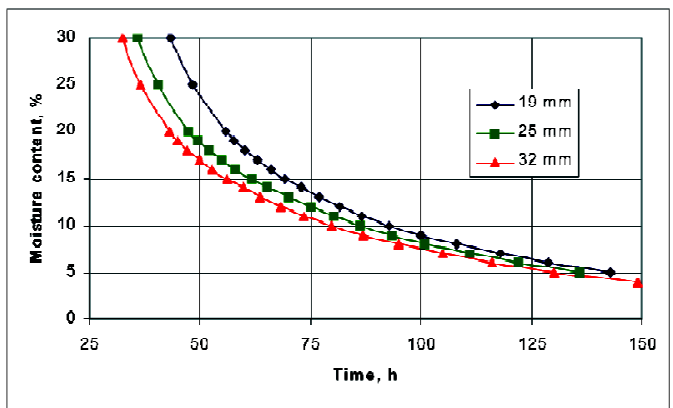

Figure 1. The influence of sticker thickness on drying time for $50 \mathrm{~mm}$ boards.

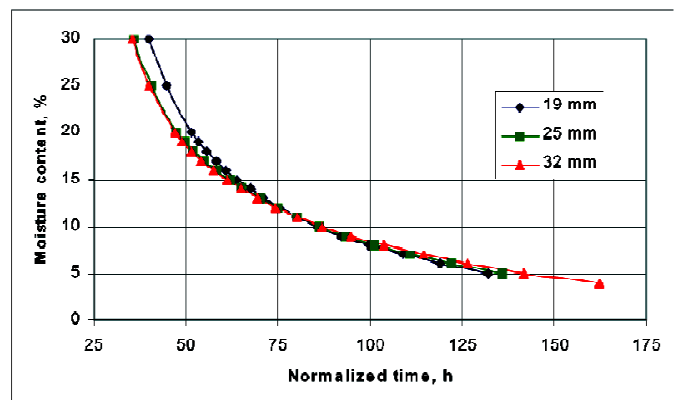

Figure 2. The influence of sticker thickness on relative kiln capacity for $50 \mathrm{~mm}$ boards.

From a quality point of view, the spread in final MC is important. The simulation model calculates the final MC for each board (actually for both sections of each board) and the MC standard deviation caused by the spatial variations in the drying climate is thus directly obtained. In reality the drying properties of each individual board vary and the variation in the final MC caused by this effect has to be added in order to get the standard deviation measured in a real kiln. This stochastic variation has in (Salin, 2002) been estimated to be $0.8 \ldots 1.5 \%$-units for $50 \mathrm{~mm}$ boards in the MC range $6 \ldots 18 \%$. Thus, if the variation caused by the position in the kiln stack is less than about $0.5 \%$-units, then the natural variation will dominate.

The calculated MC standard deviation (without the natural stochastic variation) is presented in Figure 3. The results show clearly that a considerable improvement in the final MC variation within the kiln load is obtained with thicker stickers. As the difference in capacity was small, this indicates that $32 \mathrm{~mm}$ stickers should be considered instead of $25 \mathrm{~mm}$ stickers in this particular case.

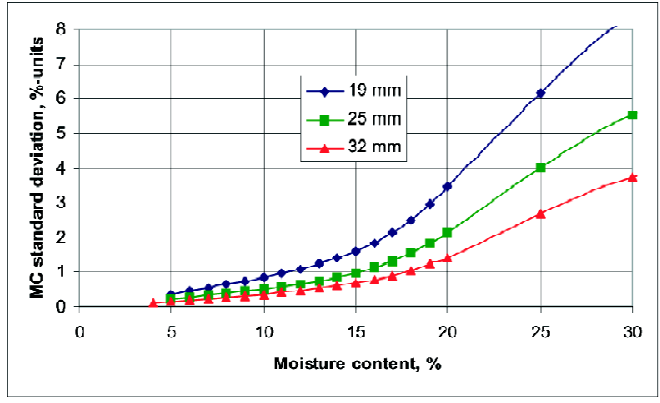

Figure 3. Influence of sticker thickness on final $\mathrm{MC}$ variation for $50 \mathrm{~mm}$ boards.

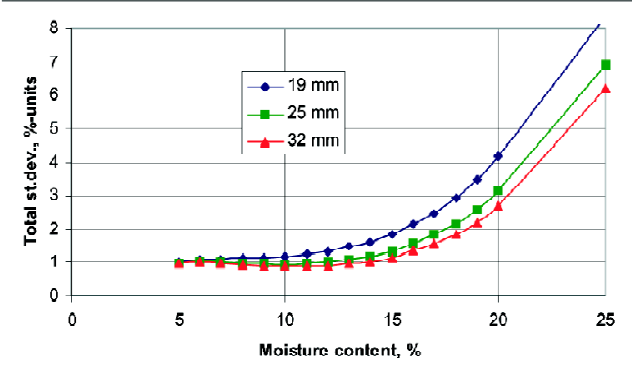

Figure 4. Influence of sticker thickness on the total final $\mathrm{MC}$ variation for $50 \mathrm{~mm}$ boards.

If the natural, random variation in the final MC, as given in (Salin, 2002) is added - by the sum of squares principle - then the result presented in Figure 4 is obtained. It is now seen that the spatial variation in the climate in the kiln is of minor importance for low target MCs in this specific case. It should also be pointed out that no equalization/conditioning phases were included in this calculation. Such phases would further decrease the influence of the sticker thickness selection on the final MC spread. 
The number of kilns required for the $32 \mathrm{~mm}$ case is about $9 \%$ higher than for the $25 \mathrm{~mm}$ case, with an equal influence on the kiln investment costs. As a final judgment, $25 \mathrm{~mm}$ and $32 \mathrm{~mm}$ stickers are in this particular case about equally good, but $19 \mathrm{~mm}$ stickers are too thin.

If the same analysis is done for $25 \mathrm{~mm}$ thick Scots pine, instead of $50 \mathrm{~mm}$, the following results are obtained. The drying curves for different sticker thickness are given in Figure 5. A rather small difference is found between 25 and $32 \mathrm{~mm}$ stickers, but the case with $19 \mathrm{~mm}$ stickers require a longer drying time.

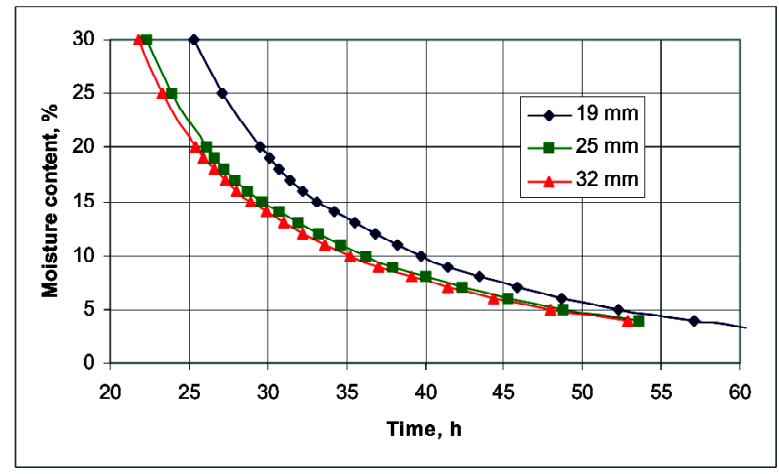

Figure 5. Influence of sticker thickness on drying time for $25 \mathrm{~mm}$ boards.

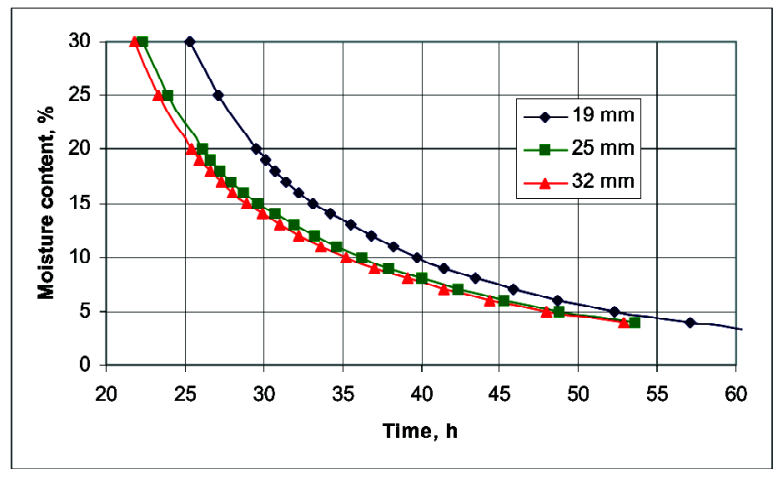

Figure 6. Influence of sticker thickness on the relative kiln capacity for $25 \mathrm{~mm}$ boards.

When the difference in timber volume in the kiln is accounted for, Figure 6 is obtained in the same way as Figure 2. Now it is clear that $32 \mathrm{~mm}$ stickers is not a favorable option for drying of $25 \mathrm{~mm}$ boards.

Figure 7 presents the standard deviation in the final MC. Only the variation caused by the spatial variation in the drying climate is included in Figure 7, not the random natural variation. Especially for the $19 \mathrm{~mm}$ sticker thickness the variation in MC is high and it seems thus that $25 \mathrm{~mm}$ sticker thickness is best suited for $25 \mathrm{~mm}$ boards. 


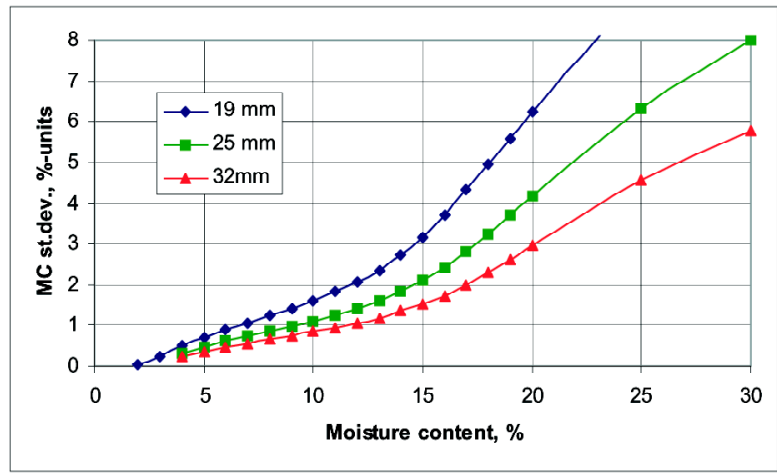

Figure 7. Influence of sticker thickness on final $\mathrm{MC}$ variation for $25 \mathrm{~mm}$ boards.

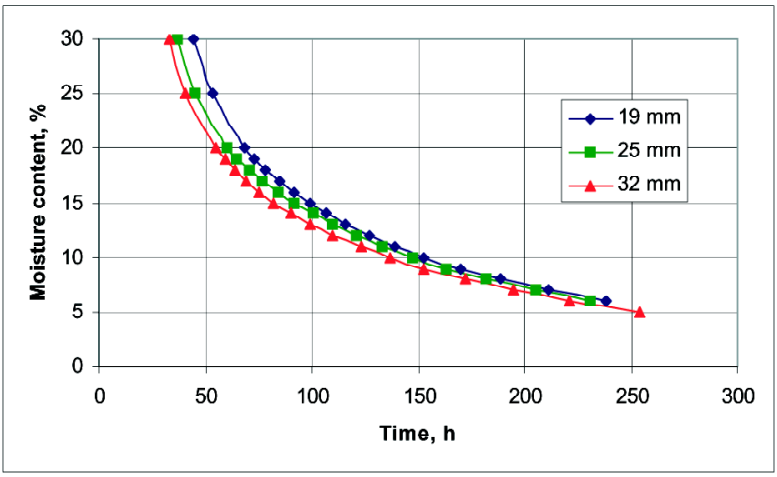

Figure 8. Influence of sticker thickness on drying time for $75 \mathrm{~mm}$ boards.

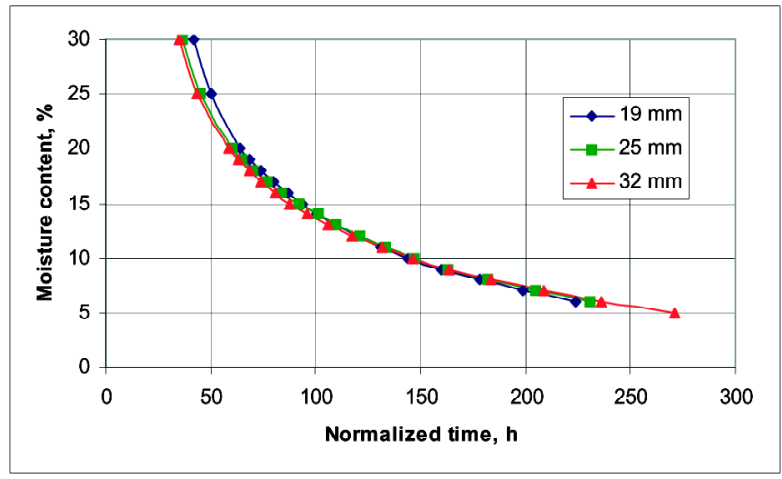

Figure 9. Influence of sticker thickness on the relative kiln capacity for $75 \mathrm{~mm}$ boards.

Next, the same calculations for $75 \mathrm{~mm}$ boards are presented. As seen in Figure 8, the sticker thickness does not influence the drying time very much. When the difference in timber volume is accounted for, as in Figure 9, even a smaller difference is found. Figure 10 presents the final MC variation caused by the spatial difference in the drying climate. The variation is in all cases rather small and it is obvious that the natural variation in timber properties will be a dominating factor and the sticker thickness is thus not critical. The conclusion is that both 19 and $25 \mathrm{~mm}$ stickers are possible, but $32 \mathrm{~mm}$ restricts the timber volume unnecessarily. 


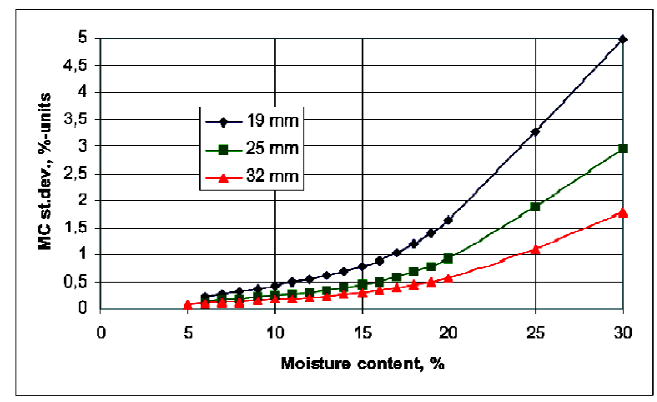

Figure 10. Influence of sticker thickness on the final MC variation for $75 \mathrm{~mm}$ boards.

All simulations described above were done for the same kiln. It may be interesting to check how a change in the blow depth influences the results. In the following drying of $50 \mathrm{~mm}$ boards in a kiln with a blow depth of $10 \mathrm{~m}$ instead of $5 \mathrm{~m}$ is considered. All other kiln data are kept constant. Figure 11 gives the drying curves for the different stickers. A comparison with Figure 1 shows that the influence of the sticker thickness is more pronounced now and that the drying time is considerably longer.

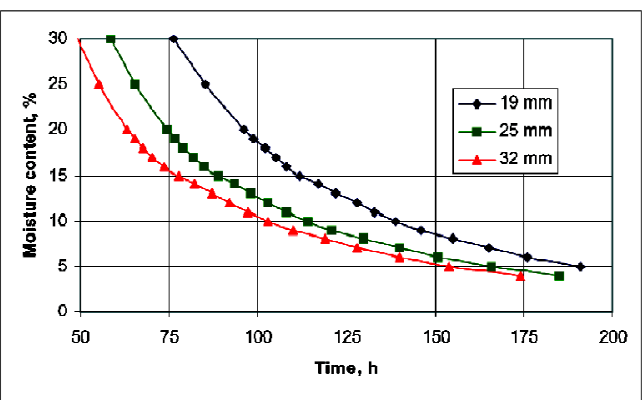

Figure 11. Influence of sticker thickness on drying time for $50 \mathrm{~mm}$ boards in a bigger kiln.

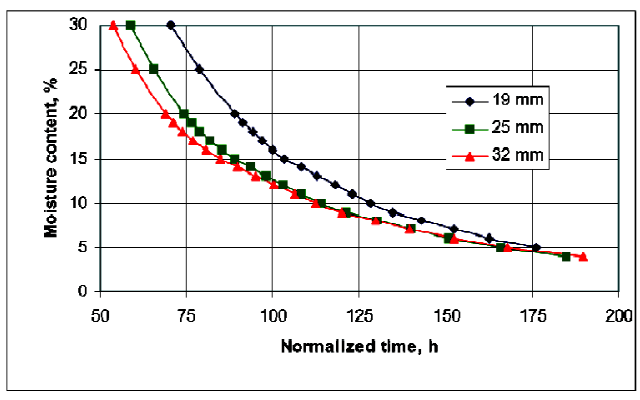

Figure 12. Influence of sticker thickness on the relative kiln capacity for $50 \mathrm{~mm}$ boards in a bigger kiln.

In Figure 12 the timber volume corrected drying time is presented and it is seen that the $19 \mathrm{~mm}$ sticker thickness is not a good choice.

As seen in Figure 13 the final MC variation is high which favors a selection of $32 \mathrm{~mm}$ thick stickers. The increased blow depth has thus changed the optimal sticker thickness towards thicker stickers.

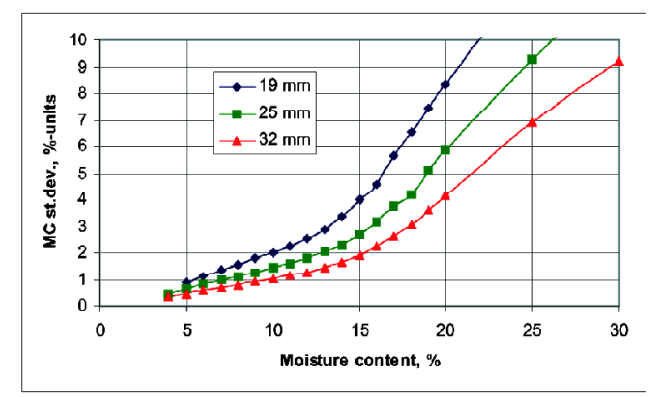

Figure 13. Influence of sticker thickness on the final $\mathrm{MC}$ variation for $50 \mathrm{~mm}$ boards in a bigger kiln. 
As seen from Figures 1 and 11 the drying time has increased by $30 \ldots 60 \%$ depending on the situation. The same increase in capacity would be the result if two small kilns ( $5 \mathrm{~m}$ blow depth) were used instead of one big kiln $(10 \mathrm{~m})$. It seems that this may cover the higher investment. It should be noted, however, that the air velocity has been about $3 \mathrm{~m} / \mathrm{s}$ in all cases studied, which is a rather low value for the $10 \mathrm{~m}$ blow depth kiln.

In summary, based on the simulations done for Scots pine, a sticker thickness of $25 \mathrm{~mm}$ seems to be a good compromise. This is obviously true for Norway spruce also, and perhaps for many other softwood species too.

\section{PREDICTION OF FINAL MC VARIATION}

The previous section showed that the variation in the final MC - caused by spatial variations in the climate in the kiln - depends on many parameters, such as board thickness, sticker thickness, blow depth, air velocity and of course drying schedule. It would be good to have a simple formula by which an order of magnitude estimate for this variation could be calculated. Such a formula could be used in the planning of the drying process in a given kiln, or for the design of new kilns.

If the $\mathrm{MC}$ variation due to the natural, random variation in board properties is excluded, the origin of the variation is the change in climate (dry bulb temperature) as the drying air passes through the kiln stack. This change is directly linked to the drying rate. A higher drying rate requires more heat of evaporation, which results in a higher temperature drop across the load. The evaporation associated with each space between two adjacent board layers is thus characterized by B.du/dt, where B is board thickness and du/dt is the drying rate. How much this evaporation affects the temperature of the air as it passes through this space is characterized by $\mathrm{L} /(\mathrm{S} \cdot \mathrm{v})$, where $\mathrm{L}, \mathrm{S}$ and $\mathrm{v}$ are blow depth, sticker thickness and air velocity, respectively.

The drying rate, $\mathrm{du} / \mathrm{dt}$, is associated with the instant rate, but in this case we want to use an average rate for the whole process. The rate is thus instead expressed as

$\Delta \mathrm{u} / \mathrm{t}$, where $\Delta \mathrm{u}$ is the difference between initial and final MC and $\mathrm{t}$ is the total time needed to achieve this change. Now it should be possible, as a first approximation, to estimate the final MC standard deviation as a function of a single index that is given by the following expression.

Index $=\left(\frac{\mathrm{B} \Delta \mathrm{u}}{\mathrm{t}}\right)^{\mathrm{n}}\left(\frac{\mathrm{L}}{\mathrm{Sv}}\right)^{\mathrm{m}}$

where

$\mathrm{B}=$ board thickness in $\mathrm{mm}$

$\Delta \mathrm{u}=\mathrm{MC}$ change in $\%$-units

$\mathrm{t}=$ drying time in hours (heating up and conditioning excluded)

$\mathrm{L}=$ blow depth in $\mathrm{m}$

$\mathrm{S}=$ sticker thickness in $\mathrm{mm}$

$\mathrm{v}=$ air velocity between board layers in $\mathrm{m} / \mathrm{s}$

$\mathrm{n}, \mathrm{m}=$ adjustable parameters.

The parameters $\mathrm{n}$ and $\mathrm{m}$ should now be determined from calculated values for the MC standard deviation for a multitude of different cases. If no fan reversal is used during the drying cycle, then the expression $\mathrm{L} /(\mathrm{Sv})$ is directly linked to the difference in temperature between the pressure and suction sides of the timber load. In that case it seems that $\mathrm{m}=1$ is an appropriate selection. If fairly frequent fan reversals are used then the "active" temperature difference is given by the temperature in the center of 
the load and the average temperature on either side of the load. If it is assumed that the temperature changes according to an exponential curve upon passage through the stack, then it can be concluded that $\mathrm{m}=2$ would be a good choice.

In more than 100 different cases the MC standard deviation has been calculated for different final MC:s with the aid of the simulation model. In these cases a fan reversal period of 60 minutes was used. All the parameters in the Index-expression were varied in order to cover a multitude of possible timber drying situations. When the calculated MC standard deviations and the corresponding Index-values were compared it turned out that $\mathrm{m}=2.0$ gave the best correlation, as expected. It was further found that $\mathrm{n}=1.2$ was best suited for different final MC levels. Figures 14 and 15 illustrate the result.

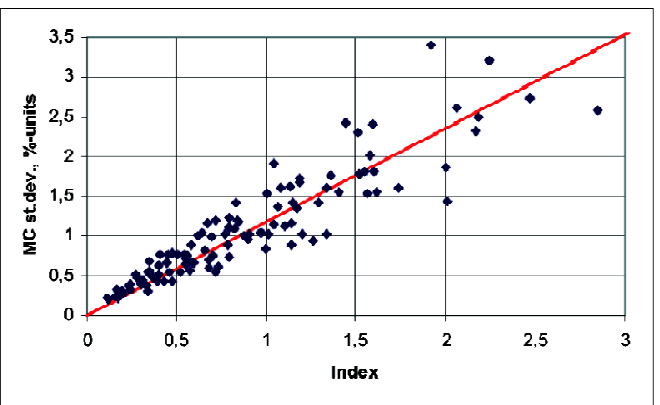

Figure 14. MC standard deviation for $12 \%$ average $\mathrm{MC}$ as a function of Index $(\mathrm{n}=1.2$ and $m=2$ ) for a kiln with airflow reversal.

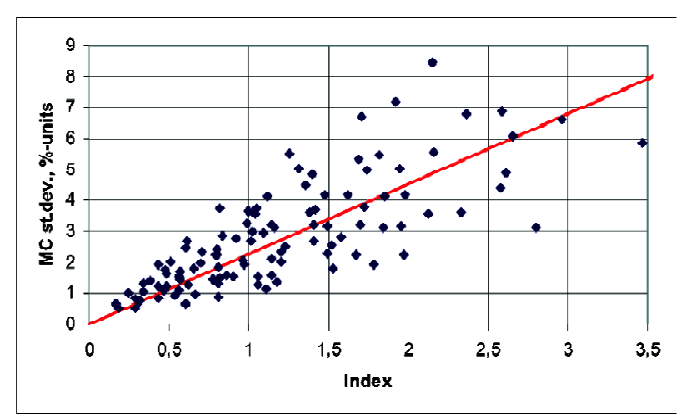

Figure 15. MC standard deviation for $18 \%$ average MC as a function of Index $(\mathrm{n}=1.2$ and $\mathrm{m}=2$ ) for a kiln with airflow reversal.

Figure 14 presents the calculated standard deviation as a function of the proposed Index in the case that the average final $\mathrm{MC}$ is $12 \%$. Figure 15 gives the corresponding result for an average final $\mathrm{MC}$ of $18 \%$. It should be noted that in all these cases no equalization or conditioning stages are included and further that the standard deviation includes only the variation due to the spatial variation in the climate in the kiln.

The drying temperature is not directly incorporated into the Index expression of equation (1). However, the drying rate $(\Delta \mathrm{u} / \mathrm{t})$ depends on the temperature as a higher rate can be used without checking if the temperature level is higher. In this way the temperature has an influence on the calculated MC standard deviation. A better correlation would perhaps be the result if the temperature were included as a separate parameter in the Index.

According to a rule of thumb - often proposed in Scandinavia - the blow depth should not exceed the air velocity doubled, in order to get an acceptable final $\mathrm{MC}$ spread, i.e. $\mathrm{L} \leq 2 \mathrm{v}$. The results above indicate that this rule is simplified too much. Applying the same approach for normal kilns with frequent fan reversals $(\mathrm{n}=1.2$ and $\mathrm{m}=2)$ gives as a new rule that the Index according to equation (1) should not exceed 0.5 .

Simulations of the same type have been done also for kilns without airflow reversal. When these results are correlated with the corresponding values for the Index, it turns out that $\mathrm{m}=1.0$ is a suitable value for this case, as expected. It is further found that the value $\mathrm{n}=0.8$ gives an acceptable correlation. The results obtained are presented in Figures 16 and 17. There seems to be two separate groups in Figure 17. The main reason is that fewer sets of input data combinations were used for the preparation 
of Figure 17 com-pared to Figure 15. "Extreme" combinations were overrepresented and "normal" combinations underrep-resented which has left the center part rather empty. However, this result shows again that the temperature should have been included in the Index as a separate variable and not only indirectly through the drying rate.

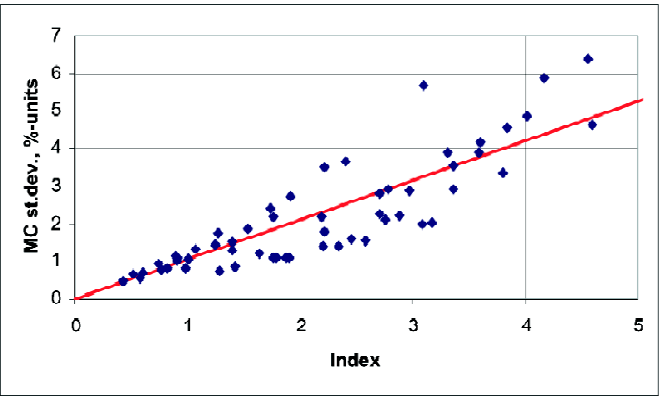

Figure 16. MC standard deviation for $12 \%$ average $\mathrm{MC}$ as a function of Index ( $\mathrm{n}=0.8$ and $\mathrm{m}=1)$ for a kiln without airflow reversal.

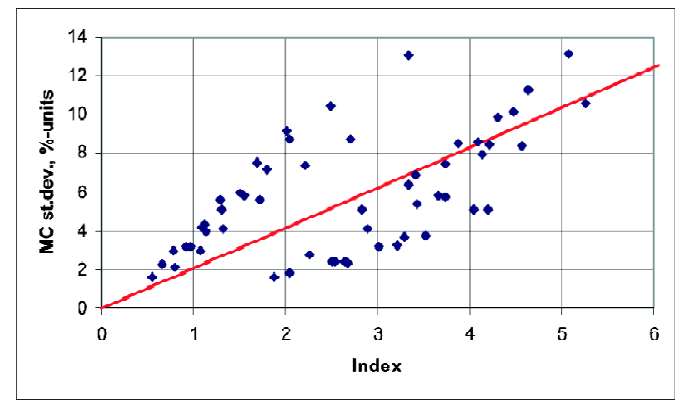

Figure 17. MC standard deviation for $18 \%$ average $\mathrm{MC}$ as a function of Index $(\mathrm{n}=0.8$ and $\mathrm{m}=1$ ) for a kiln without airflow reversal.

For kilns without airflow reversal, a rule of thumb can also be stated in the same way as above. The maximal recommended value for the Index according to equation (1) would in this case ( $\mathrm{n}=0.8$ and $\mathrm{m}=1$ ) be 0.5 i.e. the same value as for kilns with airflow reversal. It should be noted that in the calculations for Figures $14 \ldots 17$ conditions have been selected that also include very high MC standard deviations, in order to get a wider view of the entire situation.

\section{CONCLUSIONS}

It has been shown that a sticker thickness of about $25 \mathrm{~mm}$ is best suited for drying of Scots pine and probably for many other softwoods also, when kiln capacity and final MC standard deviation is considered. Further a simple method is presented for the calculation of an order of magnitude estimate of the expected final MC standard deviation based on kiln parameters. These results have been obtained with a global timber drying simulation model, TorksimGlobal. Such a model is a valuable tool for calculations of the type presented in this study.

\section{NOTE}

\$PThis paper was first presented at the IDS-2004, Sao Paulo.

\section{LITERATURE}

Salin, J.G. 2001. Global modelling of kiln drying, taking local variations in the timber stack into consideration. $7^{\text {th }}$ International IUFRO Wood Drying Conference, Tsukuba, Japan, July 9-13.

Salin, J.G. 2002. The timber final moisture content variation as a function of the natural variation in wood properties and of the position in the kiln load. An evaluation using simulation models. $4^{\text {th }}$ COST E15 Workshop, Santiago de Compostela, Spain, May 30-31. 
